\title{
La derecha chilena y los principios legitimadores del pre y post golpe de Estado de 1973*
}

\author{
The Chilean right and the legitimating principles of the pre and post \\ coup d'état of 1973
}

\author{
Jorge Olguín Olate**
}

\begin{abstract}
Resumen: En el presente artículo se plantea como objetivo general la realización de un análisis histórico-político a los principios legitimadores que justificaron el golpe de Estado y la posterior dictadura cívico militar que se instauró en Chile en 1973. Se propone como hipótesis de investigación que el proyecto de la Escuela Nacional Unificada del gobierno de la Unidad Popular, que buscaba desde el sistema escolar la construcción de un "hombre nuevo" - sin Dios-, fue el principal antecedente legitimador que incitó finalmente a que civiles y militares de derecha interrumpieran la constitucionalidad del Estado. Posteriormente a este acontecimiento, las autoridades golpistas se preocuparon de sacralizar desde el ámbito cultural su propia matriz de principios legitimadores, los cuales políticamente deben ser estudiados como ideología y teológicamente como doctrinaria religiosa. La afirmación anterior es relevante como objeto de estudio, pues indudablemente posee significativas implicancias en el actual desarrollo político, social y económico de Chile.
\end{abstract}

Palabras Clave: Escuela Nacional Unificada, Golpe de Estado de 1973, Principios legitimadores, Dictadura cívico militar

\begin{abstract}
In this article it is proposed as general objective the realization of a historical-political analysis to the legitimating principles that justified the coup d'état and the subsequent military civil dictatorship that was established in Chile in 1973. It is proposed as a research hypothesis that the project of the Escuela Nacional Unificada of the Unidad Popular government, which sought from the school system the construction of a "new man" - without God - was the main legitimating antecedent that finally incited civilians and right-wing military to disrupt the constitutionality of the State. Subsequent to this event, the coup authorities were concerned to sacralize from the cultural sphere their own matrix of legitimating principles, which politically should be studied as ideology and theologically as religious doctrinaire. The above
\end{abstract}

\footnotetext{
* Artículo elaborado a partir de algunos de los resultados de mi inédita tesis doctoral, titulada "Legitimación, institucionalización y operacionalización de la violencia de Estado bajo la dictadura cívico militar chilena, 1973-1990", Universidad de Chile, 2016.

** Chileno. Doctor en Historia, Universidad de Chile. Magíster y Licenciado en Historia, Pontificia Universidad Católica de Chile. Académico Jornada de la Facultad de Ciencias Políticas y Administración Pública de la Universidad Central de Chile. Jolguino@ucentral.cl
} 
statement is relevant as an object of study, since it undoubtedly has significant implications in the current political, social and economic development of Chile.

Keywords: Escuela Nacional Unificada, Coup d'etat of 1973, Legitimating principles, Civic-military dictatorship

Recibido: 28 abril 2017

Aceptado: 12 agosto 2017

\section{Introducción}

Tras el triunfo del socialista Salvador Allende en la elección de 1970, se inició la segunda fase deslegitimadora para la matriz de creencias de la élite conservadora chilena. Esta etapa concluyó con una violenta reacción golpista de Estado por parte de las FF.AA. y Carabineros, el 11 de septiembre de 1973.

A partir de estudios sobre los miedos sociales se ha logrado determinar que durante esta fase las élites de derecha manifestaron un incremento del terror, pues veían como el proceso reformista iniciado bajo la administración de Eduardo Frei Montalva -primera fase deslegitimadora- decantaba bajo el gobierno de la Unidad Popular (UP) en una "revolución" de carácter democrático". Para la derecha chilena parecía ser cierta la predicción de que Frei Montalva era el "Kerensky chileno"2.

A pesar de la intensa campaña del terror que mediáticamente levantó la derecha política en sus medios de comunicación ${ }^{3}$ y de la pública defensa que hicieron de la propiedad privada en la campaña presidencial de $1970^{4}$, se debe considerar que si bien el candidato Salvador Allende no logró la mayoría absoluta de los votos para consagrarse inmediatamente como Presidente de la República, el tercio de votos que sacó el candidato democratacristiano, Radomiro Tomic, pueden llevar a la conclusión que sumadas ambas votaciones, la sociedad chilena en su mayoría no deseaba frenar el proceso de transformaciones socioeconómicas iniciadas bajo el gobierno anterior. El problema pasaba entonces por la radicalización o no de este proceso reformista. Fue bajo este escenario de cambios sociopolíticos que el proceso revolucionario socialista debutaba en Chile.

\footnotetext{
${ }^{1}$ Freddy Timmermann, El gran terror. Miedo, emoción y discurso. Chile, 1973-1980, Santiago, Copygraph, 2014, p. 84.

${ }^{2}$ Manuel Fuentes, Chile al borde de una trampa, Santiago, Glomar, 1989, p. 126.

${ }^{3} \mathrm{La}$ revista de derecha PEC denunciaba por esos años la existencia de un pacto secreto entre los candidatos Tomic y Allende, en Ibid., p. 120.

${ }^{4}$ El punto central del programa de gobierno del candidato Jorge Alessandri era la defensa de la propiedad privada, en Verónica Valdivia, Nacionales y gremialistas, el parto de la nueva derecha chilena, 1964-1973, Santiago, Lom, 2008, p. 370.
} 
Tras el mencionado proceso eleccionario de 1970 la derecha quedó en shock. Un apesadumbrado General Carlos Prats relata en sus memorias que connotados personajes de este sector político pasaron por su hogar solicitando una reacción militar ante el inesperado -aunque todavía relativo- triunfo del candidato de la UP. Prats relata que dos días después de la elección de Allende, lo visitó el empresario Ricardo Claro, quien, "amargado por la derrota de Alessandri... me pregunta por el pensamiento de las FF.AA." . Situación que se repetiría días más tarde con la visita que le realizó el civil militarista Jorge Prat ${ }^{6}$. Inclusive, el mismo Prats recuerda que un importante dirigente demócrata cristiano le informó que el Ex Presidente Eduardo Frei Montalva estaba esperando un autogolpe de Estado antes de que asumiera Allende ${ }^{7}$.

Todo lo anterior llevó a que durante los dos meses que mediaron entre el triunfo electoral relativo de Salvador Allende y su ratificación por parte del Congreso Nacional, se produjeran una serie de sucesos reactivos de la derecha chilena, muchos de ellos sin ninguna estrategia definida, culminando en asesinatos sin sentido, como el que afectó al Comandante en Jefe del Ejército, General René Schneider.

Nada de lo anterior impidió la ratificación legislativa como Presidente de la República de Salvador Allende. Se iniciaba entonces un proceso de características revolucionarias que debía profundizar, al interior de la institucionalidad vigente, las reformas sociales de corte progresista iniciadas por el gobierno anterior. Asimismo, el Programa de Gobierno de la UP incluía una serie de otros cambios estructurales, como las nacionalizaciones del cobre y de la banca privada o la profundización de la Reforma Agraria, todo lo cual formaban parte de un proyecto revolucionario mayor, que en esencia alteraba las legitimidades de la matriz ideológica doctrinaria de la élite conservadora chilena.

Hacia el segundo año del Gobierno de la UP, la derecha había logrado polarizar Chile en aspectos políticos y socioeconómicos. Así y todo, la profundización del proceso revolucionario iniciado por Salvador Allende todavía era parte de la institucionalidad democrática, por tanto, su ejercicio continuaba siendo legítimo para la élite conservadora. Además, fortalecida la oposición política por la alianza entre la Democracia Cristiana y el Partido Nacional en la denominada Confederación Democrática (CODE), existía la posibilidad cierta de triunfar en las próximas elecciones congresales de marzo de 1973. De ser así, bajo el CODE se pretendía obstaculizar "democráticamente", vía mayorías en las cámaras del Congreso Nacional, las profundas reformas sociales que se estaban llevando a cabo bajo el gobierno de la UP.

Lamentablemente para la derecha, el voto pro gobierno en esas elecciones siguió alto, no alcanzando las mayorías suficientes para frenear desde el hemiciclo las reformas de Allende. Pero un simple acontecimiento veraniego de 1973, entregó el principal argumento legitimador para justificar por la fuerza la caída del gobierno de la UP. Una filtración mediática del Ministro de Educación, Jorge Tapia, proponía iniciar una reforma

${ }^{5}$ Carlos Prats, Memorias, Santiago, Pehuén, 1985, p. 166.

${ }^{6}$ Ibid., p. 170.

${ }^{7}$ Ibid., p. 173. 
educacional de fundamento marxista conocida como Escuela Nacional Unificada (ENU). En líneas generales la ENU proponía:

La construcción de una sociedad socialista basada en el desarrollo de sus fuerzas productivas, la superación de la dependencia económica, tecnológica y cultural, el establecimiento de nuevas relaciones de propiedad, y la auténtica democracia y justicia social garantizada por el ejercicio efectivo del poder del pueblo ${ }^{8}$.

De implementarse la ENU, la derecha chilena visualizaba su posible y tal vez definitiva derrota cultural. Perder desde la educación su hegemonía cultural sobre la sociedad chilena, conllevaba para este sector político extraviar el sentido máximo de su existencia, pues con este instrumento ellos habían transmitido "la creencia en determinados valores perennes" así como la implementación de una moralidad que había inducido "espontáneamente a la aceptación de la autoridad" 9 .

Bajo esta contextualización histórica, se propone como hipótesis de investigación que el proyecto de la ENU fue el antecedente legitimador que aceleró la intervención militar de 1973. Todo esto en relación a que la derecha chilena ha operacionalizado su marco de creencias y sus posteriores acciones bajo una matriz de pensamiento que políticamente es una ideología y teológicamente se sustenta en una serie de doctrinas religiosas.

Esta premisa historiográfica viene a perfeccionar la tradicional comprensión del proceso histórico político que culminó en el golpe de Estado de 1973, puesto que más allá de las acciones de sabotaje que realizaban los grupos más ultras de la derecha chilena, así como las operaciones políticas que otros actores realizaban desde sus espacios de poder, ya sea al interior o fuera de la institucionalidad vigente, lo cierto es que al estudiar los principios del marco de creencias culturales de la derecha chilena, se ha logrado determinar que éstos se operacionalizan en las acciones terrenales a partir de justificaciones de carácter político ideológico que se sostienen a su vez bajo una serie de principios de origen teológico, fundamentalmente de origen católico tomista.

De esta manera, los principios legitimadores como el bien común, el orden, el derecho a rebelión, la desigualdad de los seres humanos, entre otros, descienden culturalmente "desde el cielo" hasta el marco de creencias de la élite conservadora chilena. Posteriormente desde allí se legitima su accionar terrenal en los ámbitos políticos o socioeconómicos.

Esta síntesis teopolítica, posterior al golpe de Estado de 1973, se transformó en uno de los antecedentes fundamentales que civiles y militares utilizaron de manera instrumental, para desde la "legalidad" vigente elaborar una nueva Carta Fundamental. Esta Constitución debía proyectar la construcción de un Estado nación de sólidos principios conservadores, puesto que la matriz ideológica doctrinaria con la cual ésta fue elaborada poseía la misma naturaleza. Lo anterior tiene implicancias coyunturales relevantes para el desarrollo sociopolítico actual de Chile, ya que su manifestación, por ejemplo, en el ámbito

\footnotetext{
${ }^{8}$ Ascanio Cavallo, Memorias. Cardenal Raúl Silva Henríquez, Santiago, Copygraph, 2009, p. 464.

9 Javier González (Ed.), Setenta y cinco preguntas. La derecha. Un enfoque chileno, Santiago, Instituto de Estudios Generales, 1991, pp. 73 y 87.
} 
económico, está marcado por una altísima desigualdad social y en el plano de la gobernanza por una escasa democratización de sus estructuras políticas.

Para analizar este complejo proceso histórico se ha utilizado una metodología de fuentes primarias, sustentada en la memoria de los actores de esta época. Estos testimonios han quedado registrados en una serie de entrevistas, biografías, autobiografías, cartas y documentos oficiales de la época. Estas fuentes fueron sistemáticamente ordenadas, clasificadas y comparadas no solo entre sí, sino también a partir de un selecto cuerpo bibliográfico secundario, proveniente especialmente desde la historiografía conceptual ${ }^{10}$ y cultural $^{11}$, así como de estudios resultantes de investigaciones transdisciplinarias nacionales, derivadas desde la ciencia y filosofía política ${ }^{12}$.

En este sentido, los planteamientos teóricos de la Historia Conceptual de Koselleck permite la realización de un profundo trabajo exegético -concepto a concepto-, con lo que se alcanza una mejor comprensión hermenéutica del discurso de los actores de la derecha chilena, tanto en su tiempo como en su espacio. Si lo anterior se complementa con el enfoque de la Nueva Historia Cultural, se logra entonces comprender de manera más holística las representaciones culturales contenidas en el discurso de los actores de la temporalidad que se propone en esta investigación.

\section{La ENU y el temor de la élite conservadora chilena}

Con la irrupción pública del proyecto de la ENU, los actores de la derecha, inclusive los que veían con moderación el proceso reformista de Allende ${ }^{13}$, se unieron en torno a crear el escenario propicio para ejercer lo que ellos consideraban el legítimo "derecho de rebelión" al gobierno de la UP. Ante la propuesta de la ENU, entre marzo y agosto de 1973, políticos de derecha; representantes de las FF.AA.; de la Iglesia Católica; de los gremios ramales de los empresarios y de los medios de comunicación de masas reaccionaron virulentamente ante el proyecto educativo ${ }^{14}$.

Este proceso de rebeldía tuvo un hito significativo para la derecha chilena con el Acuerdo de la Cámara de Diputados del 23 de agosto de 1973, es decir, con un público llamado de un "Poder del Estado" a la deliberación de las FF.AA y Carabineros, pues para ellos, el Ejecutivo ya carecía de toda legitimidad teopolítica.

Para la Armada de Chile -por estar conjurando desde los tiempos del gobierno de Frei Montalva-, la ENU implicaba la consumación del proceso de concientización marxista de Chile $^{15}$. Para el Almirante Vicente Huerta, el repudio a la ENU fue "la primera advertencia

\footnotetext{
${ }^{10}$ Reinhart Koselleck, Futuro Pasado. Para una semántica de los tiempos históricos, Barcelona, Paidós, 1993.

${ }^{11}$ Lynn Hunt, The New Cultural History, Berkeley, University of California Press, 1989.

12 Renato Cristi, El pensamiento político de Jaime Guzmán. Una biografía intelectual, Santiago, Lom, 2011.

${ }^{13}$ Simon Collier y William Sater, Historia De Chile, 1808-1994, Madrid, Cambridge University Press, 1998, p. 301.

14 VV.AA, Pedro Ibáñez Ojeda. Empresario, político y educador, Viña del Mar, Universidad Adolfo Ibáñez, 2000, p. 194.

${ }^{15}$ Así lo recuerda el Cardenal Raúl Silva Henríquez, en Cavallo, op cit., p. 466.
} 
masiva de las Fuerzas Armadas al gobierno" de la UP ${ }^{16}$. Advertencia que el mismo Huerta tuvo ocasión de señalar directamente al Ministro Tapia, quien debió reunirse de emergencia con un sector de la oficialidad de las FF.AA. La reunión se llevó a cabo ante un repleto auditorio en el Ministerio de Defensa ${ }^{17}$. El General Prats recuerda en sus memorias que en esa reunión hablaron el mismo Huerta, el General Javier Palacios y los coroneles de Ejército Pedro Espinoza y Víctor Barría ${ }^{18}$. El Almirante Huerta recuerda que todos los expositores mencionados hablaron con libertad y en momentos con expresiones duras y en tono violento increparon al Ministro Tapia ${ }^{19}$. El General ${ }^{\circledR}$ Eduardo Iturriaga Neumann recuerda en sus memorias que cuando le tocó el turno de hablar al Ministro Tapia, él junto a sus compañeros de armas manifestaron su molestia mediante "movimientos, carraspeos y toses"20.

Para Huerta, el debate con el Ministro de Educación demostró:

1) Que el rechazo a la ENU era unánime y categórico; 2) que los uniformados podían enfrentar con éxito al gobierno de la UP en su propio terreno; 3) que por primera vez había habido (sic) un rechazo expreso y mayoritario de las Fuerzas Armadas al marxismo, y 4) que la comunidad de pareceres se produjo sin acuerdo previo. La oficialidad descubrió después de la charla que tenía un pensamiento común ${ }^{21}$.

Un Coronel anti golpista, José Domingo Ramos, señala en sus memorias que al interior de la oficialidad de tropa había una fuerte molestia con el gobierno por la ENU ${ }^{22}$. El mismo Almirante Huerta recuerda que "ignorante de la letra y del espíritu de la ENU" los oficiales de la marina adscritos a la Dirección de Servicios "se mostraban particularmente inquietos"23. Finalmente, el General de Ejército, Ernesto Baeza, recordará en una entrevista que la ENU fue una de las principales razones para derrocar al Presidente Salvador Allende ${ }^{24}$.

Los grupos más conservadores de la sociedad chilena estaban extremadamente preocupados con la ENU. El sector más progresista de la Iglesia Católica chilena debió

\footnotetext{
${ }^{16}$ Sergio Huidobro, Decisión naval, Valparaíso, De la Armada, 1989, p. 101. Federico Willoughby recuerda que el Almirante Huerta renunció al gobierno de la Unidad Popular por el tema de la ENU, en La guerra. Historia íntima del poder en los últimos 55 años de política chilena 1957-2012, Santiago, Mare Nostrum, 2012, p. 135.

${ }^{17}$ Asistieron 180 oficiales de las tres ramas de las FF.AA. Días antes, la Armada se había reunido en el Teatro Municipal de Viña del Mar para tratar el mismo tema, en Ismael Huerta, Volvería a ser Marino, tomo II, Santiago, Andrés Bello, 1988, p. 10.

${ }^{18}$ Prats, op. cit., pp. 378-379.

${ }^{19}$ Huerta, op. cit., p. 15.

${ }^{20}$ Eduardo Iturriaga, En las alas del cóndor, Santiago, Maye, 2009, p. 74. Actualmente Iturriaga se encuentra condenado por sistemáticas violaciones a los derechos humanos.

${ }^{21}$ Huerta, op. cit., p. 16.

22 José Domingo Ramos, Las cartas del Coronel. En respuesta a las que nadie le escribió, Santiago, Tierra Mía, 2001, p. 100.

${ }^{23}$ Huerta, op. cit., p. 10.

${ }^{24}$ Testimonio en Sergio Marras, Palabra de Soldado, Santiago, Ornitorrinco, 1989, p. 19.
} 
escuchar al interior del clero a su contraparte más ultra. El dominio de la matriz ideológica doctrinaria estaba en riesgo, por lo mismo, un abrumado presbítero Luis Gallardo exclamaba:

Acaso el bastardo programa de la ENU, no constituye la conculcación más criminal del derecho juvenil de pensar libremente, para pervertir desde la cuna la mentalidad del niño, a fin de convertirlo en un mero juguete parlante de la ideología marxista (...) y aquí estriba la razón fundamental por la cual la Iglesia, Maestra Suprema de los siglos y de la historia (...) condena al marxismo por ser intrínsecamente perverso, a raíz de su inspiración diabólica: es el mal en plena acción pervirtiendo desde la cuna ${ }^{25}$.

La jerarquía de la Iglesia Católica reaccionó apresuradamente ante la ENU. El biógrafo del Cardenal Silva Henríquez relata las intensas negociaciones que el prelado debió realizar ante el Presidente Allende para frenar el proyecto de la ENU. Este último le habría garantizado en un diálogo al Cardenal que "ésta ha sido una torpeza y yo me comprometo a que será postergado" 26 . Lo cierto es que los acontecimientos de la época señalan que si bien el 12 de abril de 1973 el Ministro Tapia bajó el proyecto de la ENU, éste, al iniciar un viaje, no pudo impedir que sus principales asesores ministeriales continuaran públicamente insistiendo en la viabilidad de la ENU; radicalizando aún más el conflicto ${ }^{27}$. Con el transcurso de los días, la agudización del problema ayudó a unificar más a la oposición, incorporando nuevas adhesiones no vinculadas ideológicamente a la derecha política.

Por consiguiente, con una oposición fortalecida tras la polémica pública por el proyecto de la ENU, cualquier diálogo, como el que se llevó a cabo a fines de agosto de 1973, entre el Presidente Salvador Allende y uno de los principales líderes de la oposición, el democratacristiano Patricio Aylwin, estaba decisivamente condenado al fracaso.

Lo anterior tiene sus matices. Si bien el tema de la ENU fue el principal argumento justificatorio que la élite conservadora necesitaba para legitimar el derecho a rebelarse ante la autoridad política ${ }^{28}$, todavía, bajo un estado de derecho, era necesario fundamentar desde el ámbito jurídico constitucional su actuar insurrecto ${ }^{29}$. En otras palabras, era necesario legalizar la legitimidad. Fue así que comenzó a planificarse la redacción del conocido Acuerdo de la Cámara de Diputados del 23 de agosto de 1973. Declaración que la derecha política ha utilizado hasta el día de hoy para justificar el "derrocamiento legal" del gobierno de la UP.

\footnotetext{
${ }^{25}$ Luis Gallardo, Dolorosa encrucijada de Chile, Santiago, Encina, 1973, p. 93.

${ }^{26}$ Cavallo, op. cit., p. 465.

${ }^{27}$ Collier, op. cit., pp. 301-302.

${ }^{28}$ Por mucho tiempo, inclusive bajo dictadura, el tema de la ENU continuó siendo instrumentalizado para legitimar el golpe de Estado. Por ejemplo, en un documento de circulación interna de las FF.AA. se lee que la ENU "permitiría controlar y concientizar a los niños desde los jardines infantiles hasta la universidad", en Técnicas soviéticas para la conquista del poder total. La experiencia comunista en Chile, s/c, s/e, s/a, p. 119.

${ }^{29}$ Cuando la derecha se dio cuenta que no podía derrotar por vía democrática al gobierno de la Unidad Popular, comenzó a generar las condiciones de "legitimidad" dentro de la legalidad para dar el golpe de Estado, en Valdivia, op. cit., p. 383.
} 
Asimismo, hubo otras declaraciones, como las de la Corte Suprema y del Colegio de Abogados. En éstas igualmente se realizaron abiertos llamados a la rebelión de las FF.AA. y de Carabineros. Desde este momento también, asesores jurídicos de los cuerpos armados, especialmente de la Marina y la Fuerza Aérea, comenzaron a trabajar en las orientaciones de los futuros bandos militares que eventualmente se aplicarían una vez interrumpida la democracia chilena ${ }^{30}$.

Para la derecha, las declaraciones de la Cámara de Diputados y del Poder Judicial eran los eslabones finales, mediante los cuales, dos poderes del Estado, el Legislativo y el Judicial, expresaban la "inconstitucionalidad" del tercer poder del Estado, el Ejecutivo de Salvador Allende. El ex Patria y Libertad, Manuel Fuentes Wendling, relata en sus memorias que en el Acuerdo legislativo de la Cámara Baja participaron seis democratacristianos y tres nacionales ${ }^{31}$. Jarpa recuerda que si bien la declaración "fue acordada y redactada por los diputados del Partido Nacional y de la Democracia Cristiana, igualmente fue consultada a algunos senadores, entre ellos Patricio Aylwin" 32.

Asimismo, es relevante que el punto "e" del Acuerdo estaba referido exclusivamente a la libertad de enseñanza; todo esto en clara alusión a la ENU.

Una vez que la declaración fue finalizada, fue votada en la Cámara Baja, siendo aprobada por 81 votos a favor y 43 en contra. Lamentablemente para la derecha, el mencionado Acuerdo no tenía fuerza legal, pues para hacer efectiva la destitución del Presidente de la República, el ordenamiento jurídico de 1925 contemplaba una Acusación Constitucional y no el mencionado Acuerdo de la Cámara Baja ${ }^{33}$. En realidad, a estas alturas, ese antecedente poco importaba. Para la oposición era relevante crear el clima propicio para dar el golpe de Estado definitivo.

Militares en retiro que tuvieron una importancia fundamental en el origen y desarrollo del golpe de Estado de 1973, como el Almirante Patricio Carvajal, son enfáticos en señalar que con este Acuerdo se aceleró la intervención golpista de las FF.AA. y de Carabineros ${ }^{34}$. Otros militares de menor rango, como el hoy Coronel en @ Cristián Labbé, vieron en este Acuerdo de la Cámara la "legitimidad de origen" para el golpe de Estado". Así también lo recuerda el ex líder del entonces Partido Nacional, Sergio Onofre Jarpa, para quien, tras esta declaración, la acción golpista de los militares "estaba en el aire"36.

\footnotetext{
${ }^{30}$ En el plano jurídico, después de la elección congresal de 1973, el Almirante Rodolfo Vio, más el Coronel de la Fuerza Aérea, Julio Tapia y el abogado civil Rubén Díaz comenzaron a preparar "la justificación jurídica del golpe, que se formulará en el futuro Bando número 5", en Jorge Magasich, Los que dijeron que “No". Historia del movimiento de los marinos antigolpistas de 1973, Volumen I, Santiago, Lom, 2008, p. 339.

${ }^{31}$ Fuentes, op. cit., p. 158.

32 Patricia Arancibia, Claudia Arancibia e Isabel de la Maza, Jarpa. Confesiones políticas, Santiago, La Tercera- Mondadori, 2002, p. 190.

${ }^{33}$ De aprobarse la Acusación por parte de la Cámara de Diputados. El Senado de la República actuaría como juez.

${ }^{34}$ Patricio Carvajal, Téngase Presente, Santiago, Arquén, s/a, p. 183.

${ }^{35}$ Cristián Labbé, Misión cumplida. Un compromiso de honor, Santiago, Hernando de Magallanes, $1990,48$. Labbé actualmente se encuentra procesado por sistemáticas violaciones a los derechos humanos.

${ }^{36}$ Arancibia, op. cit., pp. 194 y 197.
} 
Para la derecha, la sentencia legal y legítima para el derrocamiento del Gobierno de la UP había sido transmitida directamente a las fuerzas militares desde el 23 de agosto de 1973. Lamentablemente para ellos, la dubitación del nuevo Comandante en Jefe del Ejército, General Augusto Pinochet, generaba dudas para una plena ejecución del plan golpista al interior de las dos ramas militares más convencidas del golpe de Estado, la Armada y la Fuerza Aérea. Lo anterior llevó inclusive a que en los primeros días de septiembre de 1973, algunos desesperados congresistas de derecha intentaran acelerar la destitución de Allende, mediante una acusación constitucional por demencia ${ }^{37}$.

Cuarenta y ocho horas antes del 11 de septiembre de 1973, Pinochet se convenció plenamente de participar con sus tropas en el golpe de Estado. Igualmente, pocas horas antes de la intervención militar, se logró convencer para la acción golpista a un número importante de generales de Carabineros. Sumadas las cuatro ramas militares, el éxito del levantamiento militar a lo largo de todo Chile estaba garantizado. Así lo fue. El 11 de septiembre de 1973, con escasa resistencia armada por parte de los sectores progubernamentales más extremos, el golpe de Estado de civiles y militares de derecha fue un completo éxito.

\section{Re-legitimación de la matriz ideológica doctrinaria de la derecha chilena}

Lo que viene a continuación para la élite de derecha pasaba por encontrar mayores argumentaciones que legitimasen el golpe de Estado dado por las FF.AA y Carabineros. Era necesario legitimar de origen el nuevo gobierno de facto. Si lo anterior no fuera posible, era necesario entonces legitimar desde el ejercicio, el régimen dictatorial surgido en septiembre de 1973.

En este sentido, politólogos como Norberto Bobbio, aclaran que:

Se puede emplear la legalidad a propósito del ejercicio del poder y la legitimidad a propósito de la titularidad: un poder legítimo es un poder cuyo título está fundado jurídicamente, un poder legal es un poder que se ejerce de acuerdo con las leyes. Lo contrario a un poder legítimo es un poder de hecho, (pues) la legalidad está fundada en el estado constitucional, por tanto en el estado de derecho ${ }^{38}$.

El cruce argumental entre lo legal y lo legítimo permite comprender en toda su magnitud semántica, discursos, como el del Almirante Merino, quien el mismo 11 de septiembre de 1973 señaló que "esto no es un golpe de estado... sólo se persigue el

\footnotetext{
${ }^{37}$ Huidobro, op. cit., pp. 372-382.

${ }^{38}$ Norberto Bobbio, Nicola Matteucci y Gianfranco Pasquino (Dirs.), Diccionario de política, Madrid, Siglo XXI, 2005, pp. 860-861.
} 
restablecimiento de un estado de derecho acorde con las aspiraciones de todos los chilenos, cuyo quiebre ha sido denunciado por la Ilustrísima Corte Suprema, como asimismo por la Cámara de Diputados"39. Opinión que estaba en concordancia con la de otros militares, como era el caso del General @ Odlanier Mena, para quien el Acuerdo de la Cámara Baja "fue la verdadera fecha del Pronunciamiento Militar"40.

Un rol importante en este proceso re-legitimador lo tuvieron los autores intelectuales del golpe de Estado, los civiles de derecha. En un artículo publicado al poco tiempo del quiebre institucional, el abogado Héctor Riesle afirmaba que:

El Gobierno de Allende incurrió en flagrante y evidente ilegitimidad de ejercicio, entre otras por las siguientes razones 1) por haber violado reiterada, deliberada y sistemáticamente el derecho natural (...) 2) por haber violado sistemáticamente el orden jurídico positivo (... y) 3) por haber atentado deliberadamente contra el bien común ${ }^{41}$.

Para Riesle, el gobierno de la UP se había transformado en una "tiranía", por tanto "al deponer a Allende las Fuerzas Armadas no pudieron violar la Constitución, pues el Gobierno de Allende no era constitucional, ni legítima ni legalmente constituido, sino una tiranía de facto" ${ }^{42}$, concluyendo el jurista que "por ello el pronunciamiento armado del 11 de septiembre cumplió sobradamente con todos los requisitos que el derecho y la moral imponen para hacer procedente el derecho de rebelión"43.

Para la tranquilidad moral de las FF.AA y Carabineros de Chile, un joven economista "Chicago boys", Pablo Barahona, expresaba públicamente que los cuerpos armados solamente "deben obediencia al gobierno mientras este (sic) sea legítimo"44. Opinión compartida por el joven abogado "Gremialista" Jaime Guzmán, quien, bajo el seudónimo de "Juglar", en el ejemplar de la revista Tizona aparecido en noviembre de 1973, señalaba que "a la autoridad no se le obedece por ser tal, sino por ser legítima"45, por tanto, agregaba el abogado que "el pronunciamiento militar del 11 de septiembre encuentra plena justificación moral, porque la destitución de todo régimen tiránico inspirada en la necesidad racional de restaurar las condiciones que hacen posible el bien común, no tiene carácter de sedición"46. Apreciación también compartida por otro joven líder del ex Partido Nacional,

\footnotetext{
${ }^{39}$ Alfonso Márquez de la Plata, Una persecución vergonzosa, Santiago, Andújar, s/a, p. 17.

${ }^{40}$ Odlanier Mena, Al encuentro con la verdad, Santiago, Maye, 2013, p. 125. Mena se suicidó en su hogar el año 2013, tras conocer una nueva condena por sistemáticas violaciones a los derechos humanos.

41 Testimonio en Pablo Barahona, Ricardo Cox, Juraj Domic, José Garrido, Gonzalo Ibáñez, Tomas MacHale, Sergio Miranda y Héctor Riesle, Fuerzas Armadas y Seguridad Nacional, Santiago, Portada, 1973, pp. 291-293.

${ }^{42}$ Testimonio en Barahona, Ibid., p. 298.

${ }^{43}$ Testimonio en Barahona, Ibid., p. 303.

44 Testimonio en Barahona, Ibid., p. 159.

${ }^{45}$ Testimonio citado en Cristi, op. cit., p. 228.

${ }^{46}$ Citado en Ibid., p. 229.
} 
Andrés Allamand, quien recuerda en sus memorias que "vi en el golpe una reacción no sólo legítima, sino también patriótica que interpretó a una inmensa mayoría ciudadana" 47 .

En conformidad con lo anterior, el ya mencionado Riesle dedicará un texto panegírico a los miembros de la Junta Militar de Gobierno (JMG) recientemente asumida. La idea era tranquilizar sus conciencias y legitimar las acciones de violencia política que se estaban llevando a cabo genocidamente a lo largo del país. Riesle les señalaba que "la Junta puede dictar decretos leyes, modificar la Constitución o dictar una nueva si lo estima necesario"48, ya que "por tener un título fundacional y originario enraizado directamente en el derecho natural, la potestad de la Junta está por sobre el derecho positivo, está por sobre la Constitución" "49. Por tanto para él, como para un número importante de juristas de derecha, la JMG poseería plena legitimidad de origen y de ejercicio ${ }^{50}$.

La publicidad moral del golpe de Estado también fue asumida por los gremios profesionales, como fue el caso del Colegio de Abogados que, en octubre de 1973, entregó su público respaldo a la legitimidad de la JMG, señalando en un comunicado que:

Cuando la autoridad quebranta abiertamente los derechos humanos, ya porque no es capaz de ordenar racionalmente la relación entre los miembros de la comunidad, ya porque se excede de su competencia propia, ya porque viola flagrantemente el ordenamiento positivo vigente sin justificación moral, se aparta del bien común y cae en la ilegitimidad de ejercicio y es entonces cuando, si concurren a demás otros requisitos, se admite que la comunidad pueda rebelarse ${ }^{51}$.

Asimismo, en publicaciones aparecidas tras el golpe de Estado, algunos intelectuales de derecha continuaban en la lógica de dar legitimidad al gobierno de facto. Son parte de la guerra psicológica que debía producirse en la conciencia de todos los chilenos. En un escrito, Gonzalo Ibáñez Santa María intentaba bajo argumentos morales justificar la acción golpista, pues ésta autorizaría el uso de la fuerza en caso de legítima defensa ${ }^{52}$. Por otra parte, Riesle utilizaba la hermenéutica bíblica para legitimar el accionar represivo de la JMG, ya que "el derecho divino, por boca de San Pablo, establece que las autoridades legítimas están instituidas por Dios, y señala que quien las resiste, a Dios resiste" ${ }^{53}$.

Igualmente, la guerra psicológica pasaba por sacralizar a las instituciones armadas en su papel deliberante al interior de la nación. En el prólogo de un texto sin firmante, aparecido a meses de producido el golpe de Estado, se señalaba que:

\footnotetext{
${ }^{47}$ Andrés Allamand, La travesía del desierto, Santiago, Aguilar, 1999, p. 27. Sergio Onofre Jarpa menciona en sus memorias que hacia julio de 1973 creía que el gobierno de la Unidad Popular ya era ilegítimo, en Arancibia, op. cit., p. 179.

48 Testimonio en Barahona, op. cit., p. 306.

${ }^{49}$ Testimonio en Ibid., p. 305.

50 Testimonio en Ibid., p. 289.

${ }^{51}$ Citada in extenso en Álvaro Pineda, Pinochet: verdad y ficción, Madrid, Iberia, s/a, pp. 201-209.

52 Testimonio en Barahona, op. cit., p. 26.

${ }^{53}$ Testimonio en Ibid., p. 307.
} 
La legitimidad de origen, moral y jurídica del nuevo Gobierno Militar encuentra así amplia base en la doctrina clásica de las Fuerzas Armadas y de Orden de Chile (...) cuando desbordando el campo de las pugnas ideológicas y partidistas amenazan los fundamentos mismos de la Patria, ésta encuentra y reclama en los Institutos Armados su última salvaguardia ${ }^{54}$.

Los relatos anteriores demuestran que al interior de la derecha chilena existió un claro discurso de legitimación de las acciones que interrumpieron el estado de derecho vigente. Pero ellos querían ir más allá, pues debían sacralizar la violenta represión que estaban desarrollando los militares, proceso en que participaron activamente sacerdotes católicos.

El padre Osvaldo Lira exteriorizaba a poco tiempo del golpe de Estado que:

El 11 de septiembre de 1973 señala el comienzo de una nueva época en la Historia de Chile. Ese día nuestras Fuerzas Armadas, en unión con nuestro Cuerpo de Carabineros, interpretando el sentir abrumadoramente mayoritario de la opinión nacional, expulsaron del Gobierno, en un gesto magnífico, a la pandilla de criminales marxistas que se habían encaramado en la cima del poder público ${ }^{55}$.

De igual forma, el ya mencionado presbítero Gallardo, en un pequeño texto publicado a días del golpe, sacralizaba la acción de las FF.AA al decir que "hoy, todo Chile y el mundo entero conocen el cómo y el cuándo de la brillante estrategia de las Fuerzas Armadas de nuestra patria, que solo en 24 horas sepultaron definitivamente los tiránicos sueños de corte cubano-soviético del imperialismo marxista". Continuaba el sacerdote afirmando que el nuevo orden iniciado por el gobierno dictatorial finalmente era:

Más que un epílogo de la negra y penosa pesadilla del alevoso y ruin marxismo, es el prólogo de un esplendoroso amanecer, en que todos los hijos de esta tierra, confundidos en un estrecho abrazo de amor, sacrificios y esfuerzos ciudadanos, forjarán, sin odios ni rencores, junto a nuestras beneméritas Fuerzas Armadas y Carabineros de Chile, la reconstrucción y la restauración de la nación ${ }^{56}$.

Como señalaba el abogado nacionalista Sergio Miranda Carrington, finalmente las FF.AA. "son los únicos cuerpos organizados que, vertebradamente, han conservado los valores morales" 57 . Opinión compartida por el padre Osvaldo Lira, para quien el golpe de Estado del 11 de septiembre de 1973, implicaba como fecha la conmemoración de "una nueva independencia nacional" 58 .

\footnotetext{
54 Algunos fundamentos de la intervención militar en Chile. Septiembre 1973, Santiago, Gabriela Mistral, 1974, p. 12.

55 Testimonio en Alberto Arce y Enrique Campos Menéndez (Comp.), Pensamiento nacionalista, Santiago, Editorial Gabriela Mistral, 1974, p. 20.

${ }^{56}$ Gallardo, op. cit., pp. 115-116.

${ }^{57}$ Testimonio en Arce, op. cit., p. 135.

${ }^{58}$ Testimonio en Ibid., p. 21.
} 


\section{Sacralización del marco de creencias de la derecha chilena}

La dictadura cívico militar desde un inicio reforzó su apocada matriz ideológica doctrinaria. Este reforzamiento debía vigorizar todos los principios legitimadores de su marco de creencias, fuertemente cuestionados por las reformas de los gobiernos de Frei Montalva y Allende. Para que el proceso de reconcientización fuese exitoso, se debía utilizar el principal instrumento de socialización de las élites, la educación.

Fue así como tempranamente la JMG encargó al Comando de Institutos Militares hacerse cargo de la educación en la ciudad de Santiago. Debían no solo perseguir y exterminar todo rastro de marxismo en el sistema educativo: nombrando directores o rectores en instituciones de educación primaria, secundaria y superior; persiguiendo dirigentes marxistas del gremio docente y de las federaciones de estudiantes; sino que además debían militarizar la disciplina escolar y principalmente modificar los programas de estudios del currículum escolar.

En este último punto, se preocuparon de levantar un proyecto educacional unificado y basado en lo que ellos comprendían como la "libertad de enseñanza", todo lo cual debía ser concordante con la lógica de su matriz ideológica doctrinaria, en opuesto, por cierto, al contenido de la tan vilipendiada ENU.

Lo anterior había que publicitarlo rápida y masivamente en sus medios de comunicación, por eso, a seis meses del golpe de Estado, la JMG insertaba en el diario El Mercurio el siguiente mensaje:

El Gobierno de la República de Chile postula una educación profundamente humanista y apolítica, que subordine el desarrollo de los avances científicos y tecnológicos a la realización del bienestar del hombre y haga de éste el constructor responsable del bien común nacional ${ }^{59}$.

Para los militares y civiles de derecha era importante reforzar tempranamente desde la legalidad sus principios legitimadores. En ese sentido, las autoridades del gobierno dictatorial trabajaron ardua y paralelamente en tres áreas culturales del Ejecutivo, la "Asesoría Cultural de la Junta de Gobierno, el Departamento Cultural de la Secretaría General de Gobierno y una Comisión Cultural dependiente del Ministerio de Educación" 60.

El hoy Coronel ® Cristián Labbé reflexionando sobre el proyecto educacional aplicado inicialmente bajo la dictadura, señala que "la enseñanza entera tendió al estímulo de la escala de valores morales y espirituales propios de nuestra tradición cristiano-occidental y chilena"61. Lo que no menciona Labbé, es que este nuevo modelo educacional no era exclusividad del desarrollo nacionalista corporativista que les interesaba a un número

\footnotetext{
${ }^{59}$ Citado en Francisco Álvarez, “A propósito de los programas”, Cuadernos de Educación, N 34, Santiago, abril de 1974, p. 34.

${ }^{60}$ Isabel Jara, “"'Graficar una "segunda independencia": El régimen militar chileno y las ilustraciones de la de la Editorial Nacional Gabriela Mistral (1973-1976)”, Historia, № 44, Santiago, 2011, p. 138.

${ }^{61}$ Labbé, op. cit., p. 76.
} 
importante de militares, sino que ahora formaba parte de un modelo de desarrollo económico neoliberal, que tempranamente estaba siendo aplicado por la JMG.

Documentos de la Oficina de Planificación Nacional (ODEPLAN), del primer trimestre de 1974, demuestran que Miguel Kast, estaba liderando una serie de comisiones de estudios para aplicar los nuevos matices neoliberales a la educación chilena, los cuales, por cierto, debían demostrar que eran compatibles y que además reforzaban la matriz ideológica conservadora, especialmente en lo relacionado con el principio legitimador de la desigualdad natural de los seres humanos. En uno de estos documentos de trabajo, Kast expresaba que "la política educacional debe garantizar la igualdad de oportunidades de modo que cada cual pueda desarrollar al máximo su potencial humano"62. Igualdad de oportunidades condicionada por el capital financiero, pues "para garantizar la igualdad de oportunidades, este sistema sería complementado con préstamos a largo plazo que permitirían pagar el costo de la educación"63.

Para un número importante de cientistas sociales, los antecedentes comentados anteriormente evidencian que el proceso dictatorial iniciado en 1973 fue o bien una revolución o una contrarrevolución. Que sea utilizado uno u otro concepto, dependerá de cómo se analice el proceso político anterior. Por un lado, será una revolución si las reformas políticas, sociales, económicas y culturales que se estaban aplicando bajo la dictadura implicaban una transformación radical que modificaba total e inéditamente los tradicionales pilares estructurales que fundamentaban la legitimidad de la República de Chile. Por otro lado, será un proceso contrarrevolucionario, si, manteniendo lo anteriormente expuesto, el nuevo gobierno respondía radicalmente como antítesis al proceso revolucionario del gobierno de la UP.

Lo anterior necesariamente se vio reforzado por el discurso de los mismos actores de la época. El General de la Fuerza Aérea, Nicanor Díaz Estrada, Subjefe del Estado Mayor de la Defensa Nacional en septiembre de 1973, señalaba en una entrevista a meses del golpe de Estado que "aspiramos a hacer un cambio total de la mentalidad de los chilenos y de las bases económicas, sociales y políticas de Chile" ${ }^{64}$. Con este tipo de declaraciones, el concepto de revolución que era asumido tradicionalmente como propio por la izquierda, comenzó bajo la dictadura a generar simpatías no solo por parte de algunos civiles, sino que también por parte de militares afines.

Ahora bien, el concepto revolución es necesario precisarlo académicamente. Hannah Arendt propone que "las revoluciones, cualquiera sea el modo en que las definamos, no son simples cambios" 65 . Advirtiendo que "solo cuando el cambio se produce en el sentido de un nuevo origen, cuando la violencia es utilizada para constituir una forma completamente diferente de gobierno, para dar lugar a la formación de un cuerpo político nuevo, cuando la liberación de la opresión conduce, al menos, a la constitución de la libertad, solo entonces

\footnotetext{
${ }^{62}$ Documento ODEPLAN, mayo 1974, contenido en Hernán Burdiles, El pensamiento de Miguel Kast, Santiago, Fundación Miguel Kast, 2006, p. 81.

${ }^{63}$ Ibid., p. 82.

64 Testimonio en Raquel Correa, Malú Sierra y Elizabeth Subercaseaux, Los generales del régimen, Santiago, Aconcagua, 1983, p. 103.

${ }^{65}$ Hannah Arendt, Sobre la revolución, Madrid, Alianza, 2006, p. 21.
} 
podemos hablar de revolución" 66 . Para la autora, entonces, la justificación de la violencia revolucionaria pasaría por fortalecer la libertad. Primero me libero luego obtengo la libertad ${ }^{67}$.

Una definición más radical del concepto revolución la entrega Herbert Marcuse. Para este autor la revolución es "el derrocamiento de un gobierno y de una constitución establecidos, por una clase social o un movimiento, cuyo fin es cambiar la estructura social y la estructura política" ${ }^{68}$. Siguiendo esta lógica, pero centrándose en las áreas de impacto de la revolución, Pitirim Sorokin propone la existencia de varias revoluciones, que dependen del espacio estructural que apuntan transformar, pudiendo ser políticas, sociales, económicas o culturales ${ }^{69}$. En el mismo sentido, Theda Skocpol distingue entre revolución social y revolución política, siendo la primera la más violenta ${ }^{70}$.

Bajo la lógica que ha guiado esta investigación, donde lo que ha primado es la matriz cultural por sobre las manifestaciones políticas, sociales o económicas, se concluye que a lo largo de la historia de Chile no se han producido revoluciones ni contrarrevoluciones. Lo que han existido son proyectos políticos reformistas y algunos de alcances revolucionarios, los cuales la misma historia se ha encargado de demostrar que han fracasado en su intento de subvertir la matriz cultural de la élite conservadora chilena, tal como ha acontecido en 1829-1830, 1851, 1859, 1891 y 1973.

Este fracaso de los procesos revolucionarios chilenos se explica a partir de ciertas lógicas reactivas de las élites dominantes, puesto que han respondido "oportunamente", ya sea por la razón o por la fuerza ante la irrupción de grupos políticos o sociales que han intentado subvertir su matriz ideológica doctrinaria. Estos procesos subversivos a lo largo de la historia de Chile han sido enseñanzas pedagógicas para los conservadores, puesto que han aprendido que su matriz no es estática sino dinámica en sus principios ideológicos doctrinarios.

A pesar de que en la autopercepción de los actores de la derecha chilena su definición del concepto de ideología sería antinatural ${ }^{71}$ y por tanto anticristiana, lo cierto es que bajo su pragmatismo, mientras ésta refuerce los principios legitimadores de su marco de creencias, permite a la misma nutrirse de nuevos elementos teorizantes e instrumentales, como fueron en su momento el neoliberalismo económico o el antimarxismo proveniente de la Doctrina de Seguridad Nacional.

Bajo esta perspectiva, resulta necesario establecer cómo este marco ideológico doctrinario descendió desde la teoría a la praxis, especialmente en instituciones como las

\footnotetext{
${ }^{66}$ Arendt, Ibid., p. 36.

67 Idem.

${ }^{68}$ Citado en Carlos Asensio, “Una discusión teórica en torno al concepto de Revolución”, Nómadas, $\mathrm{N}^{\circ} 34$, 2012, http://www.pendientedemigracion.ucm.es/info/nomadas/34/carlosasensio.pdf

${ }^{69}$ Citado en Mauricio Jaramillo, "Reflexiones acerca del concepto de revolución: aproximación a la literatura sobre el tema", Revista Cultura Investigativa, $\mathrm{N}^{\circ}$ 5, 2012, p. 88.

${ }^{70}$ Citado en Asensio, op. cit.

${ }^{71}$ Para Juan Antonio Widow, uno de los intelectuales de la derecha chilena, la ideología se define como "un principio de acción contraria al orden natural". Para él, por tanto, sería antinatural "la transformación de la sociedad de acuerdo a la pauta ideológica", en El hombre animal político. Orden social, principios e ideologías, Santiago, Academia Superior de Ciencias Pedagógicas de Santiago, 1984, pp. 126-127.
} 
FF.AA, pues fueron sus mandos los que jugaron un rol preponderante al interior de la Administración Pública del naciente Estado dictatorial.

Las FF.AA. dada su estructura altamente jerárquica, suelen ser más pragmáticas que reflexivas en su actuar. Lo anterior no invalida que logren, al menos los mandos superiores, sostener un marco ideológico doctrinario determinado. Por ejemplo, en una entrevista, un molesto Pinochet contra preguntaba a una periodista que lo interpelaba por las violaciones a los derechos humanos que se cometían bajo su gobierno. El ex dictador la increpaba diciéndole "¿usted ha leído a San Agustín o a Santo Tomás de Aquino? Ellos justifican todo el odio y la rabia que uno puede tener cuando la situación lo hace posible"72. Para Pinochet la "verdad es la verdad de occidente. De ese occidente amenazado por las fuerzas intrínsecamente perversas de un enemigo que busca enquistarse en él"73. Este enemigo no sería otro que el marxismo, pues esta ideología para él sería "una doctrina intrínsecamente inmoral y falsa" simplemente equivocada, como ha habido antes tantas en la historia. No. El marxismo es una doctrina "intrínsecamente perversa", lo que significa que todo lo que de ella brota, por sano que presente en apariencias, está carcomido por el veneno que corroe su raíz"75. Recordando finalmente el mismo Pinochet, el sentido espiritual de su gobierno, al señalar que "es el Creador quien nos pone frente a una realidad de equilibrio, orden y autoridad", por tanto "pido al Altísimo que nos dé luces y las fuerzas necesarias para enfrentar las difíciles tareas de Gobierno"76.

En este sentido, una mera caracterización del marco de creencias del Almirante José Toribio Merino permite concluir que este militar era profundamente católico, posiblemente el más católico de la JMG. Siendo capaz de cruzar su marco de creencias teológicas con intelectuales laicos conservadores, como José Ortega y Gasset ${ }^{77}$. Bajo este cruce de creencias, su cosmovisión del mundo era maniquea, siendo su marco de legitimidad "la ley de Dios"78. Lamentablemente el contenido del discurso del mencionado Almirante no ha sido correctamente analizado como sujeto histórico por parte de los cientistas sociales, especialmente en razón de la importancia del metalenguaje religioso utilizado por este actor, pues ha sido opacado por lo "divertido" o "caricaturesco" en la forma en que expresaba su discurso.

Ahora bien, más allá de la mera representación de este sujeto, frases como "el mundo tiene hoy un enemigo, que es el comunismo"79 o "Dios nos hizo a todos con alma, pero el diablo se las sacó a algunos, a los humanoides", van en la evidente dirección de sacralizar la brutal represión que se estaba llevando a cabo en contra de ciudadanos de izquierda;

\footnotetext{
${ }^{72}$ Su testimonio en Margarita Serrano, Personas de mundo. Entrevistas de Margarita Serrano, Santiago, ZigZag, 1990, p. 232.

${ }^{73}$ Augusto Pinochet, Política, politiquería y demagogia, Santiago, La Nación, 1983, p. 92.

${ }^{74}$ Discurso de Augusto Pinochet en Chile enciende la llama de la libertad, Santiago, Gabriela Mistral, 1975, p. 24.

75 Augusto Pinochet, Repaso de la agresión comunista a Chile, Santiago, La Nación, 1986, p. 41.

${ }^{76}$ Augusto Pinochet, El día decisivo. 11 de septiembre de 1973, Santiago, Andrés Bello, 1979, p. 167.

${ }^{77} \mathrm{Su}$ testimonio en Correa, op. cit., p. 25.

78 Testimonio en Ibid., p. 31.

${ }^{79}$ Testimonio en Ibid., pp. 33-34.
} 
acción justificada teopolíticamente para él, pues éstos serían seres "sin conciencia, sin alma"80.

Otro ejemplo más. Uno de los principales conjuradores del golpe de Estado de 1973, el Contra Almirante Vicente Huidobro, relata en sus memorias que el mismo 11 de septiembre en la tarde, mientras se trasladaba en helicóptero junto al Almirante Merino en dirección a la Escuela Militar, sobrevolaron por un Palacio de la Moneda parcialmente destruido y todavía humeante. Es ese momento Merino le expresó a Huidobro que:

Dios quiera que nunca más un gobierno caiga en manos de irresponsables o locos que lleven a nuestra tradicional democracia a ser víctima de ideas foráneas que no tienen ninguna relación con lo que es nuestro Chile y que jamás tengamos que volver las Fuerzas Armadas a hacer uso de las armas para defender la Patria de un ataque interior ${ }^{81}$.

Esta última frase es significativa para la comprensión de la legitimación del uso de la violencia directa que desde el discurso realizaban civiles y militares de derecha en contra de otros chilenos, especialmente a partir del golpe de Estado de 1973. Por ejemplo, a los pocos días de la intervención militar, el diario El Mercurio fue autorizado a salir a circulación y en una de sus páginas se publicitó una proclama de la JMG. En ésta se señalaban las orientaciones legitimadoras de las flagrantes violaciones a los derechos humanos que se estaban cometiendo a contra de miles de chilenos. Decía la nota:

Hoy nace un Chile nuevo, en que no hay vencedores ni vencidos. La patria se ha liberado de los malos chilenos que, fanatizados por la prédica de mercenarios extranjeros puestos al servicio del marxismo internacional, pretendían hacer de Chile un país de esclavos, en contra de sus más sagradas tradiciones históricas y espíritu libertario, democrático y soberano de nuestro pueblo ${ }^{82}$.

Este tipo de declaraciones son parte de la guerra psicológica del nuevo gobierno. Es lo que el historiador Freddy Timmermann ha definido como miedos sociales, en cuanto "se teme a la Junta y al Estado, porque se teme a Dios"83.

Guerra que, para los actores de la derecha chilena, había comenzado mucho antes, bajo la administración de Eduardo Frei Montalva y que ultraconservadores como Fabio Vidigal tenían la esperanza de que algún día la "divinidad" pusiera fin al que él calificaba como el gobierno del "reformador ilegítimo", pues sentenciaba Vidigal que solo "nos resta esperar que Nuestra Señora del Carmen, Patrona de Chile, intervenga" ${ }^{4}$.

\footnotetext{
${ }^{80}$ Entrevista en Serrano, op. cit., pp. 210-211.

${ }^{81}$ Huidobro, op. cit., p. 261.

${ }^{82}$ En Ana María Contador, Continuismo y discontinuismo en Chile. Discursos, Santiago, Bravo y Allende Editores, 1989, p. 57.

${ }^{83}$ Timmermann, op. cit., p. 193.

${ }^{84}$ Fabio Vidigal, Frei, el Kerensky chileno, Buenos Aires, Cruzada, 1968, p. 154.
} 
Juan Antonio Widow, uno de los intelectuales de la ultraderecha chilena, reconoce que según su marco de creencias "la violencia física es en principio legítima, debiendo guardar en su aplicación aquella proporción: es decir que es justa, en lo que toca a esta condición, si es adecuada para lograr mediante ella la restitución del orden exigido por el bien común" 85 . Por tanto, recogiendo el principio legitimador del orden jerárquico, los gobiernos "están obligados en justicia a emplear la violencia para reprimir a quienes subvierten el orden natural, único fundamento válido para una verdadera concordia social" $"$, puesto que "la imposición del orden recto, y esto ordinariamente lleva consigo la necesidad de aplicar violencia, es decir, de impedir la acción de quienes subvierten ese orden" $" 87$. Subversivos que para Widow serían todos aquellos individuos con capacidad de "violentar un orden para destruirlo"88; que para el Almirante Merino serían los "humanoides" y que para el General Pinochet éstos serían simplemente unos "seres anormales, aniquilados psicológicamente por su odio" 89 .

Asimismo, para el principal actor intelectual de la dictadura cívico militar chilena, el abogado Jaime Guzmán, el derecho humano más fundamental de la sociedad debía ser el derecho de propiedad ${ }^{90}$. Renato Cristi explica que, para los actores de derecha, las causas que justificaban la violencia de la dictadura tenían sus orígenes en los tiempos del gobierno de Frei Montalva, pues fue bajo ese mandato que se habría violado uno de sus principales principios legitimadores de la derecha chilena: el derecho de propiedad $^{91}$.

El desarrollo económico, decía Pinochet, estaba "fundado en el respeto al derecho de propiedad privada" 92 . Propiedad privada que estaba correlacionada con la libertad de los ciudadanos y, que para el mismo Pinochet, además se condicionaba a la espiritualidad de los mismos ${ }^{93}$.

Widow entrega algunos antecedentes al respecto:

Aún ciertos bienes básicos, como la conservación de la vida, no son derechos absolutos (...) el derecho a la propia vida, que en principio existe en todo hombre, supone sin embargo que el individuo no haya cometido un delito punible en justicia con la muerte, como sería, por ejemplo, un asesinato o la traición a la patria ${ }^{94}$.

Por todo lo anterior, para personajes como Guzmán el derecho de propiedad era un derecho a la libertad por sobre el de la vida, puesto que "los derechos humanos no son

\footnotetext{
${ }^{85}$ Widow, op. cit., p. 47.

${ }^{86}$ Ibid., p. 50.

${ }^{87}$ Ibid., p. 51.

${ }^{88}$ Ibid., p. 125.

${ }^{89}$ Pinochet, op. cit., p. 79.

${ }^{90}$ Cristi, op. cit., p. 175.

${ }^{91}$ Ibid., p. 176.

${ }^{92}$ Discurso de Augusto Pinochet en Chile enciende la llama de la libertad, op. cit., p. 50.

${ }^{93}$ Discurso de Augusto Pinochet en Ibid., p. 59.

${ }^{94}$ Widow, op. cit., pp. 48-49.
} 
absolutos, en el sentido de ilimitados"95; éstos "tampoco tienen igual jerarquía"96 y finalmente éstos tampoco "pueden ser violados por el Estado o por los particulares. Esto último sucede cuando un particular atenta de modo injusto contra un derecho natural de otro ser humano"97.

\section{Principios legitimadores en la Constitución de 1980}

Finalmente, en la progresión legitimadora de la dictadura cívico militar, se encuentra la obra culmine que deberá producir la legalidad jurídica constitucional de los principios legitimadores de la matriz ideológica conservadora, la Constitución de 1980. Algunos cientistas sociales basados fundamentalmente en premisas políticas, sostienen que el comienzo de la nueva constitucionalidad del gobierno de facto se encuentra en el discurso que Pinochet pronunció el 9 de julio de 1977 en el acto del cerro Chacarillas ${ }^{98}$. En esa oportunidad, en un evidente discurso de origen guzmaniano, el dictador planteó que:

Es conveniente reiterar, una vez más, que el 11 de Septiembre no significó sólo el derrocamiento de un gobierno ilegítimo y fracasado, sino que tal suceso representó el término de un régimen político-institucional definitivamente agotado, con el consiguiente imperativo de construir uno "nuevo"99.

A días del golpe de Estado y ante la consulta de ingenuos sectores demócrata cristianos de saber la fecha de retorno a la democracia, la respuesta de la JMG era que ellos trabajaban bajo "metas y no plazos". El escenario de Chacarillas era distinto. Por primera vez, de manera pública, la dictadura se abría a la posibilidad de delinear un calendario para la entrega de la potestad legal de gobernar. El componente legítimo del proceso lo definiría el propio Pinochet ${ }^{100}$. De esta manera se pueden comprender frases de su discurso en Chacarillas, en el sentido de retornar a la democracia, pero a una definida como "autoritaria, en cuanto debe disponer de una autoridad fuerte y vigorosa"101.

Ahora bien, todo lo anterior debe ser complementado históricamente. El nuevo proyecto constitucional no se inició en 1977 con el discurso de Pinochet en Chacarillas,

95 Jaime Guzmán, Escritos personales, Santiago, Zig-Zag, 1993, p. 140.

96 Ibid., p. 144.

${ }^{97}$ Ibid., p. 146.

${ }^{98}$ Roberto Thieme recuerda que Jaime Guzmán, Álvaro Puga, Enrique Campos Menéndez y Germán Becker fueron los productores del acto del cerro Chacarillas, en Manuel Salazar, Roberto Thieme. El rebelde de Patria y Libertad, Santiago, Mare Nostrum, 2007, p. 165. Gisela Silva señala en la biografía del Brigadier ${ }^{\circledR}$ Miguel Krassnoff, que éste también habría participado en la organización del acto, en Miguel Krassnoff. Prisionero por servir a Chile, Santiago, Maye, 2011, p. 116. Actualmente Krassnoff se encuentra condenado por sistemáticas violaciones a los derechos humanos.

99 Augusto Pinochet, Camino recorrido. Memorias de un soldado, tomo II, Santiago, Instituto Geográfico Militar, 1990, p. 145.

${ }^{100}$ Roberto Thieme recuerda que el General Leigh no asistió al acto por encontrarse en el sur de Chile, en Salazar, op. cit., p. 166.

101 Véase el discurso completo en Contador, op. cit., p. 63. 
sino que formó parte de un plan más amplio que se estaba aplicando inmediatamente producido el golpe de Estado de 1973, pues tal como señalaban abogados filo pinochetistas, en esa fecha temprana se sitúa el inicio de una verdadera "revolución constitucional" que culmina en la Constitución de 1980. Estos abogados, en cuanto profesores de la Facultad de Derecho de la Universidad Católica de Chile, emitieron en 1980 una declaración pública impresa en el diario El Mercurio, donde hacían un abierto llamado a la población chilena a marcar "Sí" por la nueva Constitución, puesto que "se ha demostrado que la revolución del 11 de septiembre de 1973 fue legítima por haberse cumplido todos los requisitos del derecho a rebelión" 102 .

A partir del espurio triunfo plebiscitario de 1980, la matriz ideológica doctrinaria de la derecha chilena quedó legalizada. La idea para los actores de derecha era que, teniendo o no en el futuro el control político del gobierno, los enclaves autoritarios contenidos en la nueva Constitución deberían impedir cualquier cuestionamiento a la matriz conservadora. No podía volver a repetirse lo que aconteció con la Constitución de 1925, la cual, bajo los gobiernos de Eduardo Frei Montalva y Salvador Allende habría sido fuertemente cuestionada en sus principios legitimadores.

Fue de esta manera que los "cerrojos" que resguardarían la matriz conservadora contenida en la nueva Constitución estarían contenidos en ella misma. Por ejemplo, en el plano militar la nueva Constitución creaba instituciones paralelas al poder civil, como el Consejo de Seguridad Nacional; asimismo se creaban los cargos de senadores designados y vitalicios; se determinaban altísimos quórums para realizar reformas a la misma Carta Magna y finalmente se creaba un nuevo Tribunal Constitucional con la misión autodesignada de proteger el mismo instrumento jurídico que lo había creado.

En el plano social, los cambios con la nueva Constitución pasaban por el giro de orientación de la función del Estado, pues el principio legitimador del orden social ya no provendrá de la autoridad de este último sino del mercado financiero ${ }^{103}$. Por tanto, si bien la nueva Constitución garantizaba una democracia con partidos políticos en desmedro de una orgánica con gremios, el mercado determinará las reglas del juego político, las cuales ya no serán decididas por el Estado sino por los empresarios dueños del mercado.

Por consiguiente, la Constitución de 1980 consolidó el triunfo del mercado por sobre el Estado. Solamente de esta manera se pueden comprender que principios legitimadores como el derecho de propiedad tengan actualmente más garantías que los derechos humanos y los derechos sociales. El principio legitimador de la subsidiariedad desde ese momento y hasta el presente son la garantía para los agentes privados dominantes de que tendrán un Estado garante de sus propiedades, pues tal como lo recuerda el Almirante Merino en una entrevista, hasta antes de la Constitución de 1980 "no había seguridad sobre la propiedad, elemento fundamental de la sociedad cristiana" ${ }^{104}$.

\footnotetext{
102 Citado en Jorge Hourton, Combate cristiano por la democracia, 1973-1987, Santiago, Cesoc, 1987 , p. 48.

103 Manuel Gárate, La revolución capitalista en Chile (1973-2003), Santiago, Universidad Alberto Hurtado, 2012, p. 114.

104 Testimonio en Serrano, op. cit., p. 207.
} 


\section{Consideraciones finales}

El proceso histórico analizado demuestra que la derecha chilena posee una identidad cultural propia, formada por un cuerpo de creencias espirituales heterogéneo, pero de un evidente origen cristiano católico. Esta unidad de creencias explica tanto su cosmovisión como su ejercicio práctico del poder político o socioeconómico.

Fue bajo esta comprensión histórica que se analizaron pragmáticamente los principios legitimadores de la matriz ideológica doctrinaria de la élite conservadora chilena, principalmente porque ella es capaz de responder, primero por la razón y luego por la fuerza, cuando su sobrevivencia como grupo privilegiado está en peligro de desaparecer. Así aconteció ante la serie de reformas progresistas que se aplicaron bajo los gobiernos de Eduardo Frei Montalva, pero especialmente de Salvador Allende.

En el presente estudio se pudo demostrar que la derecha chilena antes de perder su poder cultural, tanto en su totalidad como en sus alcances sociopolíticos, reacciona. Así aconteció cuando el gobierno de la UP anunció el proyecto ENU. Estaban aterrados, pues su marco cultural conservador dominante, el que legitima el injusto orden social de Chile, de unos pocos sobre otros muchos, estaba en peligro de desaparecer. Desde ese momento ellos aceleraron lo que consideraban como su "legítimo" derecho a rebelarse ante un Poder del Estado.

La derecha lo hizo con un violento golpe de Estado. Este hecho de fuerza les permitió no solo salvaguardar su tradicional autoridad social en el país, sino que, bajo el nuevo escenario político dictatorial, tuvieron la oportunidad de reforzar bajo la legalidad que le otorgaba una nueva Constitución, los tradicionales principios legitimadores de su matriz ideológica doctrinaria. De esta manera, la élite conservadora chilena lograba una vez más auto garantizarse su dominio cultural de Chile.

\section{Bibliografía}

\section{Fuentes primarias}

- Algunos fundamentos de la intervención militar en Chile. Septiembre 1973, Santiago, Gabriela Mistral, 1974.

- Álvarez, Francisco, “A propósito de los programas”, Cuadernos de Educación, N 34, Santiago, abril de 1974.

- Allamand, Andrés, La travesía del desierto, Santiago, Aguilar, 1999.

- Arancibia, Patricia, Claudia Arancibia e Isabel de la Maza, Jarpa. Confesiones políticas, Santiago, La Tercera- Mondadori, 2002.

- Arce, Alberto y Enrique Campos Menéndez (Comp.), Pensamiento nacionalista, Santiago, Editorial Gabriela Mistral, 1974.

- Barahona, Pablo; Ricardo Cox; Juraj Domic; José Garrido; Gonzalo Ibáñez; Tomas MacHale; Sergio Miranda y Héctor Riesle, Fuerzas Armadas y Seguridad Nacional, Santiago, Portada, 1973. 
- $\quad$ Burdiles, Hernán, El pensamiento de Miguel Kast, Santiago, Fundación Miguel Kast, 2006.

- Carvajal, Patricio, Téngase Presente, Santiago, Arquén, s/a.

- Cavallo, Ascanio, Memorias. Cardenal Raúl Silva Henríquez, Santiago, Copygraph, 2009.

- Chile enciende la llama de la libertad, Santiago, Gabriela Mistral, 1975.

- Correa, Raquel; Malú Sierra y Elizabeth Subercaseaux, Los generales del régimen, Santiago, Aconcagua, 1983.

- Cristi, Renato. El pensamiento político de Jaime Guzmán. Una biografía intelectual, Santiago, Lom, 2011.

- Fuentes, Manuel, Chile al borde de una trampa, Santiago, Glomar, 1989.

- Gallardo, Luis, Dolorosa encrucijada de Chile, Santiago, Encina, 1973.

- Guzmán, Jaime, Escritos personales, Santiago, Zig-Zag, 1993.

- Hourton, Jorge, Combate cristiano por la democracia, 1973-1987, Santiago, Cesoc, 1987.

- Huerta, Ismael, Volvería a ser marino, Tomo II, Santiago, Andrés Bello, 1988.

- Huidobro, Sergio, Decisión naval, Valparaíso, De la Armada, 1989.

- Iturriaga, Eduardo, En las alas del cóndor, Santiago, Maye, 2009.

- Labbé, Cristián, Misión cumplida. Un compromiso de honor, Santiago, Hernando de Magallanes, 1990.

- Márquez de la Plata, Alfonso, Una persecución vergonzosa, Santiago, Andújar, s/a.

- Marras, Sergio, Palabra de Soldado, Santiago, Ornitorrinco, 1989.

- Mena, Odlanier, Al encuentro con la verdad, Santiago, Maye, 2013.

- Pineda, Álvaro, Pinochet: verdad y ficción, Madrid, Iberia, s/a.

- Pinochet, Augusto, Camino recorrido. Memorias de un soldado, Tomo II, Santiago, Instituto Geográfico Militar, 1990.

- Pinochet, Augusto, El día decisivo. 11 de septiembre de 1973, Santiago, Andrés Bello, 1979.

- Pinochet, Augusto, Política, politiquería y demagogia, Santiago, La Nación, 1983.

- Pinochet, Augusto, Repaso de la agresión comunista a Chile, Santiago, La Nación, 1986.

- Prats, Carlos, Memorias, Santiago, Pehuén, 1985.

- Ramos, José Domingo. Las cartas del Coronel. En respuesta a las que nadie le escribió. Santiago: Tierra Mía, 2001.

- Salazar, Manuel, Roberto Thieme. El rebelde de Patria y Libertad, Santiago, Mare Nostrum, 2007.

- Serrano, Margarita, Personas de mundo. Entrevistas de Margarita Serrano, Santiago: ZigZag, 1990.

- Silva, Gisela, Miguel Krassnoff. Prisionero por servir a Chile, Santiago, Maye, 2011.

- Técnicas soviéticas para la conquista del poder total. La experiencia comunista en Chile, s/c, s/e, s/a.

- VV.AA, Pedro Ibáñez Ojeda. Empresario, político y educador, Viña del Mar, Universidad Adolfo Ibáñez, 2000.

- Vidigal, Fabio, Frei, el Kerensky chileno, Buenos Aires, Cruzada, 1968.

- Widow, Juan Antonio, El hombre animal político. Orden social, principios e ideologías, Santiago, Academia Superior de Ciencias Pedagógicas de Santiago, 1984.

- Willoughby, Federico, La guerra. Historia íntima del poder en los últimos 55 años de politica chilena 1957-2012, Santiago, Mare Nostrum, 2012. 


\section{Fuentes secundarias}

- Arendt, Hannah, Sobre la revolución, Madrid, Alianza, 2006.

- Asensio, Carlos, "Una discusión teórica en torno al concepto de Revolución", Nómadas, $\mathrm{N}^{\circ}$ 34, 2012, http://www.pendientedemigracion.ucm.es/info/nomadas/34/carlosasensio.pdf

- Bobbio, Norberto; Nicola Matteucci y Gianfranco Pasquino (Dirs.), Diccionario de política, Madrid, Siglo XXI, 2005.

- Collier, Simon y William Sater, Historia De Chile, 1808-1994, Madrid, Cambridge University Press, 1998.

- Contador, Ana María, Continuismo y discontinuismo en Chile. Discursos, Santiago, Bravo y Allende Editores, 1989.

- Gárate, Manuel, La revolución capitalista en Chile (1973-2003), Santiago, Universidad Alberto Hurtado, 2012.

- González, Javier (Ed.), Setenta y cinco preguntas. La derecha. Un enfoque chileno, Santiago, Instituto de Estudios Generales, 1991.

- Hunt, Lynn, The New Cultural History, Berkeley, University of California Press, 1989.

- Jara, Isabel, "Graficar una "segunda independencia": El régimen militar chileno y las ilustraciones de la de la Editorial Nacional Gabriela Mistral (1973-1976), Historia, N$^{\circ} 44$, Santiago, 2011.

- Jaramillo, Mauricio, "Reflexiones acerca del concepto de revolución: aproximación a la literatura sobre el tema", Revista Cultura Investigativa, N 5, 2012.

- Koselleck, Reinhart, Futuro Pasado. Para una semántica de los tiempos históricos, Barcelona, Paidós, 1993.

- Magasich, Jorge, Los que dijeron que "No". Historia del movimiento de los marinos antigolpistas de 1973, Volumen I, Santiago, Lom, 2008.

- Timmermann, Freddy, El gran terror. Miedo, emoción y discurso. Chile, 1973-1980, Santiago, Copygraph, 2014

- Valdivia, Verónica, Nacionales y gremialistas, el parto de la nueva derecha chilena, 19641973, Santiago, Lom, 2008. 